\title{
Pibid como espaço de formação docente
}

\author{
Pibid as space of teacher education
}

Pibid como espacio de formación docente

\author{
JARINA RODRIGUES FERNANDES* \\ HELOISA CHALMERS SISLA** \\ RENATA MARIA MOSCHEN NASCENTE***
}

\begin{abstract}
$\diamond$
RESUMO

O propósito deste artigo é analisar como o Programa Institucional de Bolsa de Iniciação à Docência (Pibid), da Capes, que tem sido desenvolvido no curso de Licenciatura em Pedagogia da Universidade Federal de São Carlos (UFSCar), desde 2011, vem se constituindo em um terceiro espaço de formação de professores/as. Para tanto, foram analisadas experiências narradas em entrevistas semiestruturadas por três licenciandas em Pedagogia que participaram do programa por três anos consecutivos. Ficaram evidenciadas aprendizagens relativas à escola e à diferenciação entre o Pibid e o estágio, com características de uma profissionalidade reflexiva, intelectual e autônoma, com elementos que denotam a constituição do referido terceiro espaço de formação.
\end{abstract}

Palavras-chave: Formação docente. Terceiro espaço. Pibid.

\begin{abstract}
The aim of this paper is to analyze how the Scholarship Institutional Program for Teaching Initiation - Pibid/ CAPES, which has been developed within the Education Undergraduate Course at São Carlos Federal University - UFSCar since 2011 has been developed as a third space in teachers' education. To do so, we analyzed experiences narrated by three student teachers who participated in the program for three consecutive years. We have found evidence regarding the school and the distinction between the program and the mandatory supervised practices student teachers take part during their undergraduate studies. Elements of a professional initiation were marked by reflectiveness, teachers as scholars and autonomy, with indications that the program was really providing student teachers $a$ third space of teacher education.
\end{abstract}

Keywords: Teacher education. Third space. Pibid.

\section{RESUMEN}

El propósito de este artículo es analizar cómo el Programa Institucional de Bolsa de Iniciación a la Docencia (Pibid), de la CAPES, que viene siendo desarrollado a lo largo del curso de Licenciatura en Pedagogía de la Universidad Federal de São Carlos - UFSCar desde 2011 ha empezado a constituirse en un tercer espacio de formación de profesores. Para eso, se analizaron experiencias narradas en entrevistas realizadas por tres licenciadas en Pedagogía que participaron en el programa por tres años consecutivos. Ha sido posible evidenciar el aprendizaje relacionado a la escuela y a la diferenciación entre el Pibid y las prácticas, con características relativas a una profesionalidad reflexiva, intelectual y autónoma, con elementos que muestran la constitución del mencionado tercer espacio de formación.

Palabras clave: Formación docente. Tercer espacio. Pibid.

*Pedagoga, Doutora em Educação escolar, Docente do Departamento de Teorias e Práticas Pedagógicas, Universidade Federal de São Carlos, São Paulo. E-mail: <jarinarf@gmail.com>.

**Pedagoga, Doutora em Educação escolar, Docente do Departamento de Teorias e Práticas Pedagógicas, Universidade Federal de São Carlos, São Paulo. E-mail: <heloisasisla@gmail.com.br>.

***Historiadora, Doutora em Educação escolar, Docente do Departamento de Educação, Universidade Federal de São Carlos, São Paulo. E-mail: $<$ rmmnascente@gmail.com>. 


\section{INTRODUÇÃO}

O presente estudo parte da compreensão de que a implementação do Programa Institucional de Bolsa de Iniciação à Docência (Pibid), do Ministério da Educação, gerenciado pela Coordenadoria de Aperfeiçoamento de Pessoal de Nível Superior (Capes), remete à necessidade de aprofundar a compreensão de suas implicações na formação inicial de professores/as no Brasil. Identificou-se que o Pibid se aproxima do que Zeichner (2010) denomina de terceiro espaço no contexto da formação inicial, pois, em consonância com o que propõe o autor, o programa coloca-se como campo propício capaz de ir além da mera soma de saberes oriundos da escola e da universidade. Desse modo, o presente artigo busca analisar sentidos construídos por licenciandas do curso de Pedagogia Presencial da Universidade Federal de São Carlos, campus São Carlos, que permaneceram nele desde a sua criação, a partir de aprendizagens por ele propiciadas. A questão colocada é: quais elementos do Pibid podem proporcionar a expansão de sentidos para as pibidianas, indicando a constituição de um terceiro espaço na formação docente?

Após a apresentação de considerações sobre o contexto investigado, é tecido um diálogo entre o Pibid e as contribuições da literatura sobre formação inicial de professores. Em seguida, apresentam-se os aportes teóricometodológicos advindos da teoria da atividade sóciohistórico-cultural, seguidos da indicação dos procedimentos metodológicos utilizados. Finalmente, discutem-se os resultados, seguidos pelas considerações finais.

\section{CONSIDERAÇÕES INICIAIS SOBRE O CONTEXTO INVESTIGADO}

A UFSCar participa do Pibid desde 2009, sendo o projeto institucional pautado na perspectiva interdisciplinar. O curso de Pedagogia Presencial, campus São Carlos (PPSC), tem tomado parte do programa desde 2010. Em consonância com as exigências do programa, os/as licenciados/as têm 12 horas disponíveis para realizar as inserções nas escolas e a produção de registros. Tais registros são realizados em dois formatos: diários e portfólios. Os diários, descritivos e reflexivos, são responsáveis por possibilitar um novo olhar para as ocorrências do cotidiano. Os/as licenciandos/as identificam temáticas recorrentes em sua experiência e se debruçam sobre estas para realizar o aprofundamento teórico requerido pelas situações encontradas nas escolas, a fim de aprimorar suas práticas e agregar novas aprendizagens à sua formação. Os diários constituem matéria-prima para a produção de um texto semestral (portfólio), no qual os/as licenciados/as sistematizam as reflexões de caráter teórico-prático realizadas no período.
Os/as licenciandos/as do PPSC atuaram de 2010 a 2013 em duas escolas da cidade, uma municipal e outra estadual, voltados/as para a atuação nos anos iniciais do ensino fundamental e para a educação de jovens e adultos. A equipe do PPSC em 2013 era composta por 24 licenciandos/as, três professoras supervisoras (professores/as das escolas), 10 professores/as orientadores/as e uma coordenadora (professores da universidade). As professoras supervisoras eram as profissionais das escolas responsáveis por acolher e orientar os/as licenciandos/as no ambiente escolar, intermediando as relações com gestores/as, professores/as e todos os elementos que compõem a cultura escolar. A coordenadora do PPSC assumia o papel de acompanhar o movimento dos/as licenciandos/as nas escolas, junto aos/às demais orientadores/as do Pibid e às professoras supervisoras. E participava das negociações entre demandas da escola, dos/as licenciandos/as e eixos de ação previstos no subprojeto do PPSC, bem como das reflexões teóricas e práticas suscitadas pelo processo. Os/as professores/as orientadores/as, também docentes do curso de Pedagogia, apoiavam o trabalho, ao colaborar na oferta de formações temáticas específicas. Além de compartilhar a leitura dos portfólios dos/as licenciandos/as, dialogando com os sentidos construídos pelos/as pibidianos/as, ao estabelecer relações entre prática e teoria, trazendo questionamentos, se fosse necessário, e apontando sugestões de pontos para aprofundamento do processo reflexivo.

\section{O PIBID COMO TERCEIRO ESPAÇO NA FORMAÇÃO DOCENTE}

Conforme apresentado na introdução, compreende-se o Pibid como um programa que pode ser considerado, de acordo com a perspectiva de Zeichner (2010, p. 487), um terceiro espaço na formação inicial de professores, superando a binaridade entre a formação acadêmica propriamente dita e a formação pela prática por si só:

Da perspectiva das faculdades e universidades, a solução para a desconexão entre universidade e escolas na formação de professores e na formação profissional continuada para professores da Educação Básica tem sido, habitualmente, tentar perceber maneiras melhores de trazer o saber acadêmico das faculdades e universidades para os professores da Educação Básica. Esse tem sido um modelo de fora para dentro, no qual o saber está primordialmente entre os acadêmicos e não entre os professores da Educação Básica (ZEICHNER, 1995). A criação de terceiros espaços na formação de professores envolve uma relação mais equilibrada e dialética entre o conhecimento acadêmico e o da prática profissional, a fim de dar apoio para aprendizagem dos professores em formação (ZEICHNER, 2010, p. 487). 
Entende-se que a proposta do Pibid vem ao encontro do que é defendido por Zeichner (2010) ao propiciar a articulação entre teoria e prática e pelas inserções de licenciandos/as em contextos reais de ensino e aprendizagem. Neves (2012, p. 365, grifo nosso) destaca que no "diálogo entre coordenadores, supervisores e licenciandos, há um processo de enriquecimento compartilhado, com impactos positivos tanto nos cursos de formação como nas escolas".

Ao valorizar o enriquecimento compartilhado, Zeichner (2010) convida a repensar as conexões entre a parcela de formação que ocorre na universidade e aquela que ocorre nas experiências de campo. Retoma estudos realizados sobre hibridismo desde a década de 1990, para propor a criação de novos espaços, o chamado terceiro espaço, em que todos aprendem com todos. E esse terceiro espaço tem se feito realidade em diversas situações. Romper com a lógica de que a universidade, detentora do conhecimento acadêmico, "legítimo", "superior", vai à escola para iluminá-la tem sido a tarefa empreendida. É fundamental para o sucesso do Pibid uma relação de diálogo igualitário entre todos os sujeitos envolvidos. Torna-se imprescindível a presença da professora supervisora, conhecedora do cenário escolar, que interage com os/as pibidianos/as no calor dos acontecimentos. Seu conhecimento e seu trabalho agregam muito não só aos/ às pibidianos/as, mas à própria professora coordenadora, ao oportunizar que repense problemáticas, revisite concepções e reveja posicionamentos. O papel da coordenadora de área, em sua função de auxiliar aos/às licenciandos/as a relacionar o aprendido durante as aulas na universidade e o que é vivenciado nas escolas também é extremamente relevante. De outra perspectiva, o papel do/a licenciando/a, com seus questionamentos, anseios e desejos, é crucial, pois, no momento de sua atividade junto aos/às educandos/as, cria-se uma oportunidade única de formá-lo/a numa perspectiva efetivamente reflexiva, o que contribui para o alcance dos objetivos da escola de hoje e lança sementes para a construção da escola do futuro.

Outro aspecto fortemente relacionado à possibilidade de criação desse terceiro espaço é a existência de recursos para prover bolsas a todos os envolvidos, uma forma efetiva de valorizar o trabalho de cada um dos sujeitos. Zeichner (2010) destaca que a escassez de recursos faz com que diversas instituições em todo o mundo deleguem a supervisão das inserções dos licenciandos/ as a pós-graduandos/as ou professores/as colaboradores/as, o que acarreta problemas relacionados à rotatividade, ausência de conhecimento no campo específico de formação de professores/as e desconhecimento do que é trabalhado durante as aulas dos/as licenciandos/as na graduação.
Outro destaque do autor, que se coaduna com os estudos que se tem realizado, é o reconhecimento da pertinência da utilização de investigações embasadas na teoria da atividade, no sentido de aprofundar a compreensão desses novos espaços formativos que buscam o encurtamento de uma distância historicamente construída entre universidade e escola.

\section{Pibid COMPREENDIDO COMO UMA REDE DE SISTEMAS DE ATIVIDADE}

Um conceito central na Teoria da Atividade SócioHistórico-Cultural (TASHC), fruto das obras de Vygotsky, Leontiev e Engstrom, é propriamente o de atividade. Esta concepção nasce sob o cunho da expressão trabalho. $\mathrm{Na}$ perspectiva marxiana, o ser humano constitui-se como tal porque age sobre a natureza que o circunda para produzir a própria sobrevivência. Ao produzir sua subsistência por meio do trabalho, ao modificar o mundo que está à sua volta, o ser humano sai, ele mesmo, modificado, sendo chamado a teorizar sobre a própria ação de modo a enfrentar as novas necessidades e situações, com o fim último de realizar-se como ser integral. Portanto, a concepção de atividade constitui-se em uma forma de rompimento com o dualismo provocado pela divisão injusta do trabalho que a uns impõe as tarefas braçais e a outros reserva a lide intelectual. Efetivar uma atividade é realizar a práxis: agir sobre o mundo, teorizar sobre tal ação, de modo a aprimorar a prática, tendo em vista a transformação da realidade rumo ao bem comum.

A linguagem coloca-se como locus da reflexão crítica, mediante a possibilidade de compartilhamento de sentidos e significados. Para Vygotsky (2004), os significados seriam produções sociais de natureza estável, construtos das gerações anteriores, que possibilitam que os seres humanos se situem no mundo. O papel dos significados é propiciar o acesso ao estabelecido socialmente, o que será de um modo singular internalizado pelos sujeitos, que, por sua vez, ao externalizarem o internalizado, já terão produzido os seus próprios sentidos.

Engeström (2009), considerado o responsável pela terceira geração da TASHC, defende ser necessário olhar a atividade como uma rede de sistemas de atividade. Na visão do autor, uma atividade está implicada numa teia complexa de relações envolvendo os sistemas de atividade que contêm elementos internos que se encontram em relação. Ele considera como elementos básicos da atividade aqueles apontados por Vygotsky $(2004,2007)$ - os sujeitos, o objeto da ação e os instrumentos mediadores - e aqueles destacados por Leontiev - a comunidade, as regras e a divisão do trabalho. Em síntese, os sujeitos são os 
indivíduos e grupos envolvidos na atividade. O objeto é o motivo que direciona a atividade, a sua razão de existir. Os artefatos são os instrumentos materiais ou psicológicos utilizados, tendo em vista o objeto da atividade. A comunidade é o contexto sociocultural em que acontece a atividade. As regras são as normas explícitas e implícitas que regem as relações entre os sujeitos - indivíduos e grupos envolvidos na atividade. Por fim, a divisão do trabalho é o modo como se encontram distribuídas as tarefas a serem realizadas, de forma mais negociada ou autoritária, a depender do poder exercido pelos sujeitos. $\mathrm{Na}$ visão de Engeström (2009), o objeto, motivo gerador e orientador da atividade coletiva, encontra-se em constante expansão, sendo justamente esse um dos grandes avanços propiciados pelo autor. Como os sistemas se encontram em relação, ocorre a expansão do objeto da atividade. Desse modo, o autor abre caminho para que se compreenda o ciclo expansivo da atividade, em que o próprio objeto da atividade se modifica a partir da interação dos sujeitos envolvidos na mesma, sendo que, consequentemente, todos os outros elementos são alterados.
Nessa perspectiva, compreende-se o PPSC como uma rede de sistemas de atividade, composta por atividades iniciais, intermediárias e finais (DANIELS, 2010).

\subsection{Atividades iniciais: o ingresso no Pibid}

O ingresso no Pibid é uma atividade inicial que não pode passar despercebida. Nesse primeiro momento, encontram-se dois sujeitos: o/a licenciando/a e a coordenadora do PPSC. Cada licenciando/a tem um objeto diante de si, ao se disponibilizar para o ingresso no programa. Da parte da coordenadora, há motivos próprios de cada docente da universidade, diante da perspectiva de proporcionar uma experiência significativa de iniciação à docência. Os artefatos presentes nessa atividade inicial não parecem detalhes sem importância: os dados inseridos na ficha de inscrição e o peso simbólico do termo de compromisso remetem a um rito de passagem que carrega o selo da universidade e da Capes. É momento de conhecer e assumir as regras do Pibid e ter uma visão geral sobre a divisão do trabalho proposta. A comunidade neste momento ainda não é a escola, mas a comunidade de participantes do programa. Tais relações são ilustradas na Figura 1:

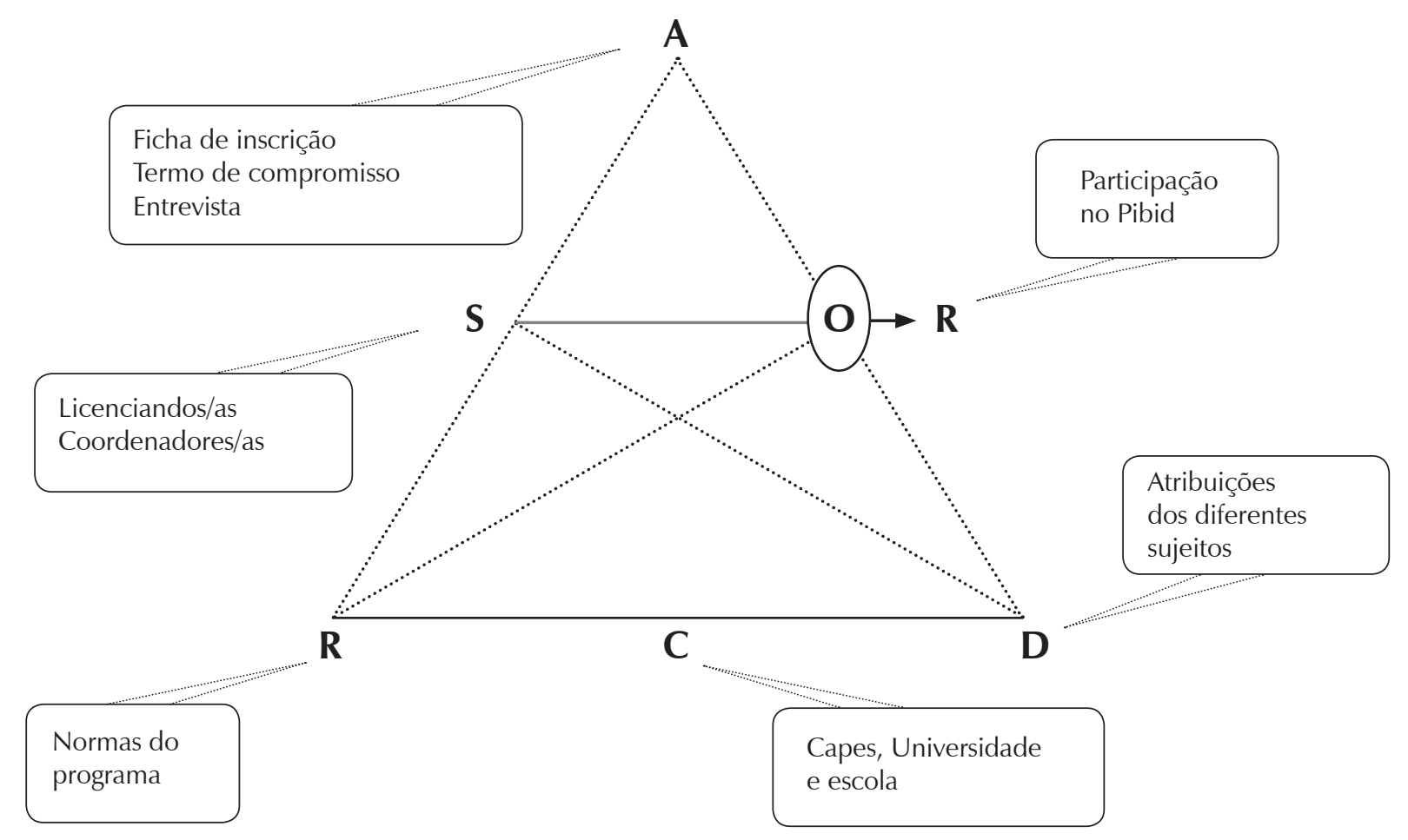

(A - artefatos mediadores; S - sujeitos; R - regras; C - comunidade; D - divisão de trabalho; $\mathrm{O} \rightarrow \mathrm{R}$ - objeto e resultado)

Figura 1. Atividades iniciais - o ingresso no Pibid 


\subsection{Atividades intermediárias: reuniões e imersão em sala de aula}

A imersão das pibidianas na escola é composta por uma rede de atividades intermediárias que se retroalimentam e provocam a expansão do objeto da atividade, representada na Figura 2.

À esquerda, tem-se a representação das reuniões semanais, com a participação de sujeitos que trazem seus diferentes sentidos para o programa: licenciandos/as, professor/a coordenador/a e professor/a supervisor/a. O objeto em comum é o planejamento, acompanhamento e avaliação das atividades a serem realizadas pelos/as licenciandos/as junto das professoras regentes e estudantes da educação básica. Os artefatos presentes nesses encontros são o projeto político pedagógico da escola, os planos de ensino, os planos de aula e os projetos ora das professoras, ora dos/as pibidianos/as e, sobretudo, o diálogo sobre sentidos construídos pelos/as licenciandos/as a partir do encontro com a cultura da escola, com as expectativas das professoras regentes e de estudantes. Conhecer a cultura escolar é conhecer a comunidade em que se está inserido, com as regras e divisão do trabalho peculiares àquele ambiente. É natural que os sujeitos, quando adentram um novo espaço, coloquem-se mais tímidos no pronunciamento dos próprios sentidos. $\mathrm{O}$ primeiro movimento dos/as licenciandos/as é comumente o de seguir as demandas apontadas pela escola. Contudo, com o tempo, passam a se sentir acolhidos/as e confiantes para propor os próprios sentidos, a partir dos significados estabelecidos, e defender propostas de realização de sequências didáticas e projetos de própria autoria, como se poderá verificar no momento da análise dos dados deste artigo.

O segundo sistema de atividade representado à direita da Figura 2 refere-se à imersão dos/as licenciandos/as no universo da sala de aula. Aqui há como sujeitos os/as licenciandos/as, a professora regente e os/as estudantes da educação básica. Como artefatos, os planos, os livros didáticos, os cadernos, as atividades copiadas e toda sorte de materiais que dão suporte ao trabalho pedagógico, assim como as inúmeras conversas que acontecem com a professora e com os/as estudantes, locus de constante apreensão de significados e construção de sentidos. A comunidade aqui remete à sala de aula, com suas regras e divisão do trabalho sob coordenação da professora. Contudo, bem se sabe que não se trata de uma comunidade isolada, mas de uma comunidade umbilicalmente ligada à escola e ao sistema educacional. $\mathrm{Na}$ imersão na sala de aula, os/as licenciandos/as têm oportunidade de visualizar como se traduzem políticas engendradas nos gabinetes dos ministérios e secretarias e como as vozes que emergem das salas de aula se relacionam com os significados estabelecidos pelos gestores do sistema. Podem aprender a alfabetizar e a ensinar conteúdos das diferentes disciplinas e buscam colocar em prática concepções e metodologias aprendidas na universidade e na própria escola. Quanto maior horizontalidade nas relações, maior aprendizagem para todos os envolvidos.

Como não poderia deixar de ser, os sistemas que compõem o que se chama aqui de atividades intermediárias encontram-se relacionados e devem acontecer de forma extremamente articulada. E assim a expansão contínua do objeto da atividade - reunião de planejamento, acompanhamento e avaliação - colocado em relação com a expansão do objeto da atividade - imersão na sala de aula - resulta a cada etapa numa nova expansão para ambos e para as aprendizagens de todos os/as envolvidos/ as: licenciandos/as, estudantes da educação básica, professores/as da escola, (supervisores e regentes) e da universidade.

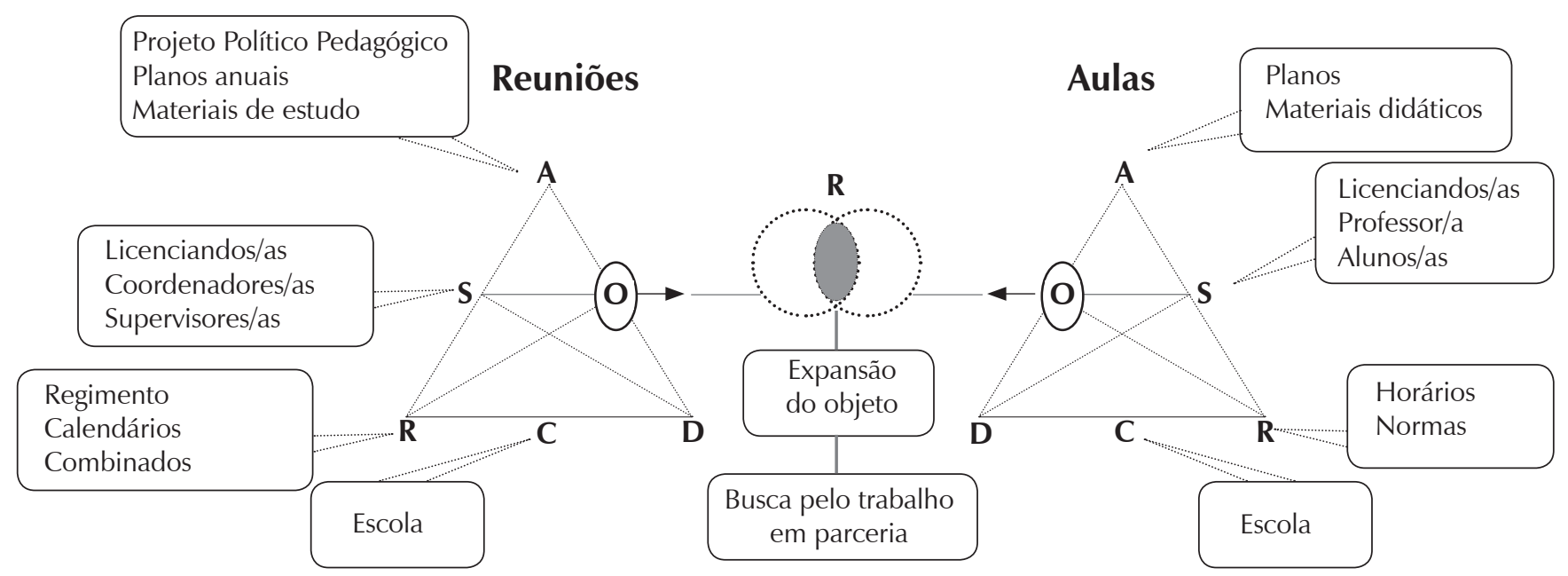

Figura 2. Atividades intermediárias: reuniões e imersão em sala de aula - sistemas de atividade em interação 


\subsection{Atividades finais: registro e sistematização}

Como atividades finais, há os sistemas relacionados ao registro e sistematização das aprendizagens realizadas. Professora coordenadora, supervisoras e licenciandos/as envolvem-se nessa tarefa imprescindível da atividade, na acepção considerada no presente trabalho (Figura 3).

Nas atividades finais, considera-se que os portfólios são o resultado esperado pelo programa para os/as licenciandos/as, assim como a apresentação ou publicação de textos a partir dos portfólios. À professora coordenadora cabe a produção de um relatório final e é esperada a produção de pesquisa sobre o processo vivenciado, como a realizada neste artigo. Como artefatos, há os registros preliminares - diários, fotos e outros -, que subsidiam a produção dos portfólios e relatórios, bem como os registros advindos da aplicação de instrumentos de pesquisa devidamente autorizados, caso se trate de produção de artigos científicos. As regras para a produção de trabalhos acadêmicos se fazem presentes na atividade, voltada à comunidade científica, objetivando alimentar e propiciar o aprimoramento da rede de sistemas de atividade instaurada pelo Pibid. É significativo que todos os sujeitos envolvidos sejam convidados ao movimento de produzir conhecimento científico, o que tem se tornado realidade nos trabalhos produzidos pelas pessoas envolvidas, tanto da escola básica quanto da universidade.

\section{Procedimentos metodológicos}

Trata-se de uma pesquisa qualitativa perpassada pelas características apresentadas por Bogdan e Biklen (1982), que realiza-se no intuito de compreender diferentes pontos de vista a fim de identificar possíveis convergências e divergências, ao iluminar o dinamismo interno das situações.

Para realizar esta investigação foram convidadas a participar de uma entrevista individual e semiestruturada as três pibidianas do grupo de 24 estudantes do PPSC que se encontravam no programa há mais tempo, de 2011 a 2013, e que aceitaram participar assinando um termo de consentimento livre e esclarecido. As entrevistas foram gravadas em áudio e transcritas. Foram escolhidos os nomes de três personagens da mitologia grega para representar o vigor e o protagonismo encontrados nas pibidianas: Ceres, Cibele e Diana.

\section{Pibid, EXPANSÃo de SENTIdos E CONSTRUÇÃO DE UM TERCEIRO ESPAÇO DE FORMAÇÃO}

Os resultados apresentados a seguir indicam aspectos da relação entre o Pibid e a escola, prosseguindo com a apresentação de diferenças apontadas pelas pibidianas entre o estágio e o Pibid, os quais trouxeram indícios de constituição de um terceiro espaço na formação docente.

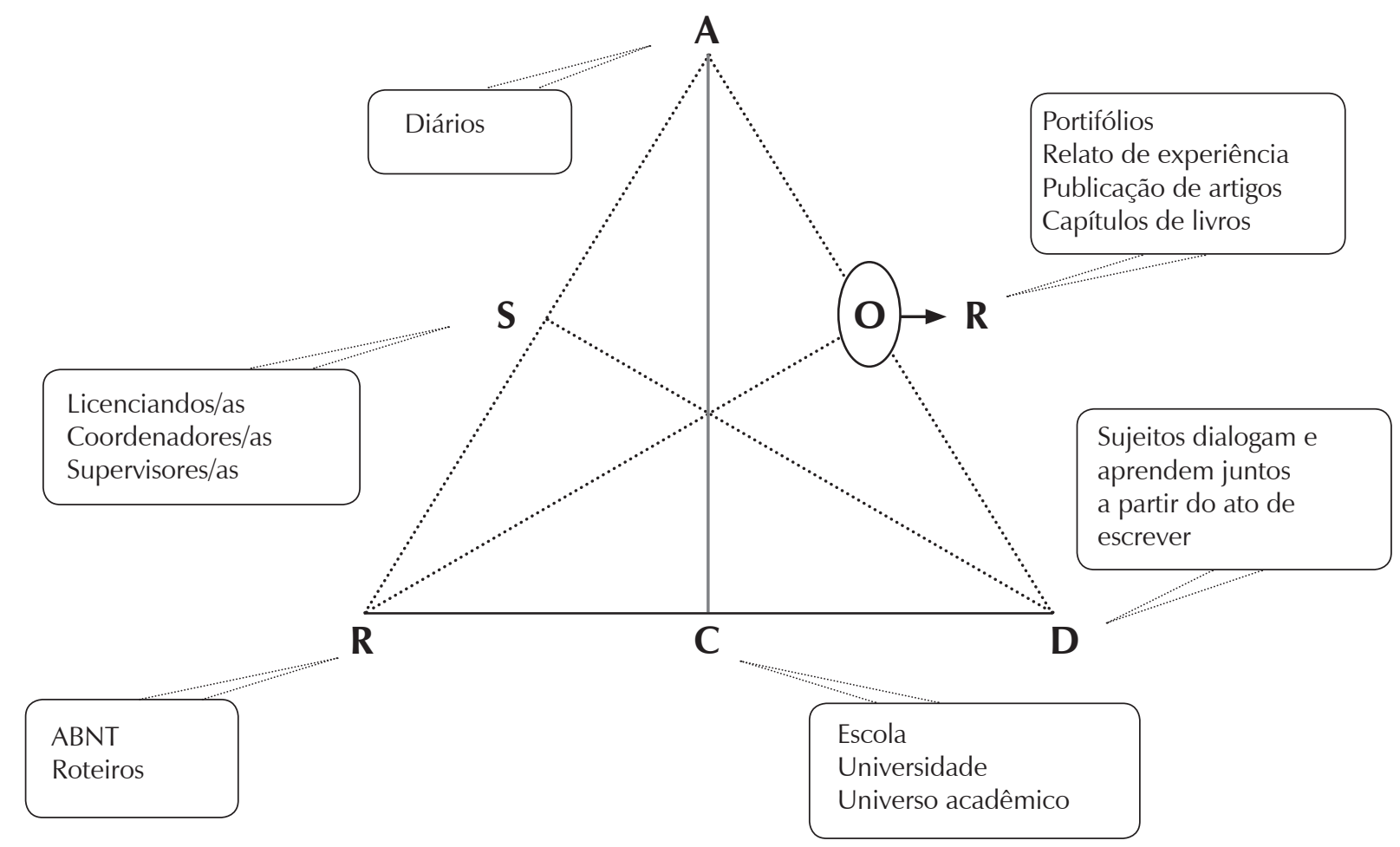

Figura 3. Atividades finais: registro e sistematização das aprendizagens construídas no Pibid 
Um dos elementos comuns nas três entrevistas foi o destaque a aprendizagens relativas à escola. Perguntouse a elas o que haviam aprendido, tanto por meio do desenvolvimento de atividades para atender às demandas da escola quanto por meio daquelas de iniciativa delas e da equipe do Pibid ${ }^{1}$.

Superando a dicotomia entre demandas da escola e iniciativas do Pibid, Ceres e Diana demonstraram compreender as nuances das relações entre o Pibid e a escola e particularmente a possibilidade de criação a partir das necessidades por esta colocadas, assim como a importância do diálogo que é preciso construir com a equipe escolar:

"A nossa ideia inicial, minha e da minha dupla, era a gente trabalhar as relações étnico-raciais, porque a gente queria muito desenvolver esse tipo de projeto, mas como no Ler e Escrever, no $l^{\mathrm{O}}$ semestre, tinha o projeto jornal, roda de jornal, nós tivemos que trabalhar roda de jornal. Era um tema que eles nos deram e a gente que fez todas as atividades, o projeto nós que criamos [...]." (Ceres)

\begin{abstract}
"Quando eu entrei no Pibid, a gente ficava meio assim, não revoltada, não é a palavra, mas assim: 'Nossa! Como assim a gente tem que fazer tudo o que a escola quer?'. Não, a gente está cheia de ideias, a gente quer criar, quer fazer as coisas, vem com toda aquela vontade. Eu lembro que eu ficava brava quando as primeiras supervisoras falavam: 'Ai, não'. Porque a escola não queria isso, a escola não queria aquilo. Por que essa escola não quer nada e convida o Pibid para atuar lá, se não está aberta a propostas?" (Diana)
\end{abstract}

Cibele manifestou sua percepção sobre a falta de autonomia da professora e da escola como um fator limitante e como um desafio a ser superado, conforme se pode notar no trecho abaixo:

\begin{abstract}
"Eles não têm uma política dentro da escola de uma gestão democrática, assim, de perguntar ao professor o que ele pensa sobre aquilo, sobre o que está acontecendo na sala dele. É muita coisa assim, faça assim [...] tem a cobrança da diretoria, eles têm a apostila do Ler e Escrever que eles são obrigados a seguir [...] tem que ter as diretrizes e etc, se não, não tem um norte pra seguir, só que fica muita pressão [...] não tem aquela coisa do professor intelectual [...] às vezes, os cursos que os professores fazem são só os cursos que o estado fala [...]." (Cibele)
\end{abstract}

\footnotetext{
${ }^{1}$ As ações mencionadas pelas pibidianas como demandas da escola foram: apoio a grupos de estudantes com dificuldades; condução da turma enquanto a professora atendia a estudantes com dificuldades; e condução de atividades da proposta do Ler e escrever e planejadas pela professora. Compreenderam as ações de iniciativa delas, sequências didáticas ou projetos sobre meios de comunicação, profissões e matemática (temas solicitados pelas escolas) e relações étnico-raciais (com destaque para a percepção da identidade e valorização do ser negro/a), gênero, sexualidade e artes (estas propostas pela equipe PPSC).
}

$\mathrm{O}$ relato de Diana tem nuances diferentes das de Cibele. Embora atuando na mesma escola, ela destaca a luta pelo que o grupo PPSC queria e o que foi possível conciliar entre as demandas da escola e do Pibid, talvez com matizes mais otimistas do que Cibele quanto ao que foi possível obter:

\begin{abstract}
"Com a instituição da escola, a gente demorou muito pra ter a oportunidade que nós temos hoje, a liberdade que nós temos hoje. A escola era muito fechada. Tudo que a gente propunha era não, não, não e não. Então, com o tempo, elas, conhecendo melhor a gestão, conhecendo melhor o trabalho do Pibid e o Pibid conhecendo melhor o trabalho da gestão, acho que deu para casar muito bem a relação. Então, hoje, pelo menos o grupo em que atuamos na escola e a gestão que está lá, eu acho que está muito bem, porque em vista do que a gente já passou e por todas as brigas que tivemos, não, o Pibid tem que ter um espaço aqui. E hoje a escola nos escuta, nós escutamos a escola. Então tenta ver o que é melhor para os dois e todo mundo sai feliz nas decisões [...]." (Diana)
\end{abstract}

É semelhante o relato feito por Ceres, que participava do Pibid em outra escola, da negociação para atuar com projetos próprios:

Ceres: "Aí, depois, a gente, as meninas, nós brigamos. Aí, a gente conseguiu no segundo semestre." Pesquisadora: "Brigando você diz assim: foi conversar com a supervisora."

Ceres: "É."

Pesquisadora: "Porque vocês sabiam que tinha essa luta."

Ceres: "É, porque a gente sabia que tinha essa luta, sabe? Porque a escola quer apoio, a escola não quer assim que a gente desenvolva muitas atividades. E as professoras também pedem apoio, porque elas precisam, é importante, né? Então no primeiro ano a gente negociou: uma parte ficava no apoio e a outra parte a gente desenvolvia as nossas atividades. Aí, a gente criou sequências didáticas e umas meninas criaram projetos."

Ceres reitera a importância da escolha do que vai propor à escola, ao mencionar a luta por maior liberdade nas ações do Pibid, de forma que assumissem o preparo e a condução de sequências didáticas ou projetos, criados por pibidianas. Afirma ainda que a principal solicitação da escola é de apoio a crianças com dificuldades, ao passo que as licenciandas queriam trabalhar com sequências didáticas e projetos criados por elas, cujos temas, já mencionados anteriormente, eram voltados para a educação das relações étnico-raciais, de gênero e artes.

De diferentes formas, os relatos indicam que as pibidianas buscavam se apropriar da docência, sem 
cisão entre quem planeja e quem executa, em direção à omnilateralidade na profissão (e na vida). Aprenderam ainda a negociar suas demandas com a escola, um saber importante para docências transformadoras da escola e da sociedade. Assim foi, tanto para Ceres e Diana, que indicavam satisfação com o resultado das lutas, que expandiu as possibilidades dos objetos envolvidos nas atividades, quanto para Cibele, que exercitou e ampliou suas reflexões sobre a falta de autonomia docente e de gestão democrática na escola. Segundo as três entrevistadas, essa autoria e protagonismo difere das experiências do estágio:

"[...] eu acho que o Pibid é o melhor auxílio que a gente tem na faculdade, porque a gente faz os estágios, mas é totalmente diferente. Nos estágios, você fica no fundo da sala apenas observando a professora e, no Pibid, nesses três anos, a gente teve um contato com tudo, com a professora, com os alunos, com as vivências dos alunos e com a gestão." (Diana).

“[...] foi a partir da prática no Pibid que eu comecei a ter essas dúvidas: 'Ah, eu não sei alfabetizar'. Eu ficava doida, mas não, é normal porque realmente a gente tem a teoria na universidade, mas a gente só vai aprender mesmo tentando colocar essa teoria na prática e indo atrás de mais formação. Eu acho que só com os estágios da faculdade não dava, porque muitos estágios, por mais que não fosse a intenção da universidade, você ficava mais na observação..." (Cibele)

"Porque a gente não fazia nada, a gente só ficava no apoio, sabe? Parecia estágio, aí a gente brigou porque a gente queria fazer atividades [...].

A gente vê no cotidiano da escola, porque no Pibid é diferente do estágio porque você está sempre mais na escola." (Ceres)

$\mathrm{Na}$ compreensão das entrevistadas, elas realizaram mais no Pibid porque a participação na escola era mais intensa, ao longo de todo o ano, uma vez por semana. A participação nos planejamentos das escolas no início e no meio do ano lhes deu mais acesso ao projeto pedagógico e oportunidade de negociar as demandas do Pibid. A relação delas com a escola era mediada por alguém de dentro desta (a professora que era supervisora do Pibid). E a proximidade maior e mais frequente com as professoras que as recebiam levou-as a compreender elementos da docência e a respeitar saberes das professoras que não se presenciam em muitas das experiências de estágio, nas quais se observam dificuldades dos/as licenciandos/as de se colocarem no lugar da professora e compreenderem a dinâmica escolar:
"Tive supervisoras ótimas, sabe? E a nossa relação com a supervisora é muito importante, faz toda a diferença, porque ela tem o conhecimento prático do dia a dia da escola, dos limites sabe? Ela sabe o que a gente pode fazer e vem, conversa com a gente." (Ceres)

"Quando a professora está ali no mesmo ritmo que você, ela te ajuda, vê tua dificuldade. Ela já pede para intervir, já puxa um gancho com alguma coisa. A gente atuou na sala de uma professora que a gente estava dando uma atividade. E saiu uma palavra porcentagem, no meio, poxa, e a gente tirou o chapéu para a mulher, porque no meio da atividade ela já puxou uma aula de porcentagem e ai a gente falou: 'Nossa! Será que um dia a gente vai conseguir fazer isso?'." (Diana)

"Ela ia atrás do conhecimento mesmo e dava muita dica assim pra gente, sabe? Da experiência dela, de como fazer. Eu aprendi muito com ela. Uma pena que ela teve que ir embora e eu percebi também que eu tinha muita defasagem teórica, na faculdade, e pra poder atuar, eu tive que ir atrás com a ajuda da coordenadora da escola e com a ajuda dessa professora principalmente..." (Cibele)

É de se observar que essa compreensão do fazer docente, além do respeito que as três dedicaram às professoras da educação básica, não as torna adaptadas e conformadas à cultura escolar. Isso pode ser constatado pelos relatos das negociações de demandas do Pibid e das críticas que fizeram à autonomia docente e da escola (já mencionados antes); à não aprendizagem, que deveria ser a principal função da escola; e às avaliações externas desvinculadas da aprendizagem das crianças, dentre outras críticas. Desse modo, verificou-se que os sentidos construídos puderam expandir-se tanto numa perspectiva de criticidade quanto de compreensão de elementos da docência e da gestão escolar, distanciando-se do danoso conformismo e aproximando-se de um caminho de construção de novos futuros para a escola. Diana conseguiu entender, inclusive, os limites da atuação do Pibid em relação ao trabalho da professora, que está com a turma a semana toda: "E nós só vamos uma vez por semana, ficamos uma hora na sala. Então é dificil a gente trabalhar todas as questões. A professora vai trabalhando durante a semana" (Diana).

A percepção de Diana sobre os limites de sua atuação na escola, os elementos apontados nas falas de Ceres e Cibele quanto às diferenças entre o Pibid e o estágio e a possibilidade de conduzirem seus próprios projetos no Pibid parecem indicar que se trata de uma experiência menos fracionada e mais integradora da escola do que a do estágio, como ficou evidenciado na fala de Diana: "Nesses três anos, a gente teve um contato com tudo, com a professora, com os alunos, com as vivências dos alunos e com a gestão". 
Se as pibidianas reconhecem as aprendizagens no Pibid dos elementos meso e macro, não deixam de diferenciar alguns apontamentos sobre os elementos micro, relacionados à sala de aula. Destacaram, assim, a pesquisa para o planejamento de atividades, a condução do ensino, a necessária flexibilidade para alterar o rumo de uma aula, a reflexão sobre a própria prática e a relação com a turma e os/as estudantes. Dentre as aprendizagens da docência no Pibid, o planejamento mobilizou a atenção das licenciandas e representou aprendizagens importantes de significados essenciais na profissão docente. Embora não houvesse questão específica sobre o planejamento no roteiro das entrevistas, elas indicaram que o preparo de aulas no Pibid requereu estudo e pesquisa, e duas delas, Cibele e Diana, estabeleceram diferenças quanto ao preparo das aulas de regência nos estágios, como disse Cibele: "Eu amadureci muito fazendo os planos de aula, tendo que pesquisar". Diana afirmou que o Pibid requer mais e de forma regular, pois toda semana precisava preparar as inserções. E comparou sua tranquilidade, quando precisou planejar a aula para a regência do estágio, com a inquietude das colegas, que não sabiam qual atividade ou ideia escolher e não tinham noção de quanto conteúdo poderiam trabalhar em uma aula.

Ao relatar uma tentativa malsucedida de um jogo de boliche no pátio, Diana considera que atividades fora da sala de aula requerem um planejamento mais cuidadoso, para evitar a dispersão das crianças: "Elas corriam pelo pátio inteiro, e a gente ficando louca, pedindo para ficarem quietas, e elas não ficavam, jogavam a bola e chutavam a bolinha. Foi uma loucura".

$\mathrm{Na}$ aprendizagem sobre a condução de aulas, seja no apoio, seja em sequências didáticas e projetos propostos por elas, alguns aspectos se destacaram, como a percepção da necessária plasticidade requerida para mudar os rumos numa aula, ou de uma aula para outra, e a importância dos diferentes tipos de reflexão sobre a própria prática, como atestam os trechos que seguem:

\footnotetext{
"Você tem que saber por que seus alunos não estão aprendendo, o que está acontecendo. Será que a minha didática está errada? Ou será que está acontecendo alguma coisa com o aluno? Então eu acho que é isso: a gente tem que ir percebendo, e a prática dá muito isso. Talvez eu vá lecionar com outra visão por causa do Pibid, e penso que não é que eu não vá ter problemas, eu sei que vou ter, coisas que eu vou bloquear, às vezes, que eu vou ter que ir atrás, só que eu acho que não vou sofrer tanto quando eu começar a trabalhar." (Cibele)

"A gente aprende lá no Pibid que o que você planeja nem sempre dá certo ou, às vezes, dá muito certo, às vezes, passa do tempo ou, às vezes, não dá tempo ou, às vezes, sobra tempo, falta material." (Diana)
}

\begin{abstract}
"Que a gente tem liberdade pra fazer, sabe? E que assim a gente pode mudar, dependendo da reação das crianças. E a gente tá sempre mudando. 'Eles não gostaram disso, então vamos fazer diferente', 'ah, foi muito teórica a aula, vamos dar mais prática', 'ah, teve pouca prática, vamos dar mais teórico'." (Ceres)
\end{abstract}

Ao ser indagada se as mudanças também ocorriam numa mesma aula, Ceres respondeu afirmativamente: "Ah, sim, durante o tempo inteiro". Portanto, a reflexão sobre a própria prática foi percebida durante todo o processo. Esse conjunto de significados apreendidos, sobre planejamento e desenvolvimento de aulas, é parte importante dos saberes docentes, e nos depoimentos das pibidianas vai tomando sentido, o que muitas vezes não ocorre nas aulas de Didática ou nas poucas regências nos estágios.

Quanto à relação com a turma e com as crianças, observou-se que se referiam às turmas e aos/às alunos/as como se fossem seus/suas. Elas mesmas se denominavam professoras, assim como as crianças se referiam a elas como "professora":

\begin{abstract}
"Eu tenho alunos hoje, nesse 5o ano, na escola, que falam: 'Ah, professora, eu quero ser médico, eu quero ser advogado'." (Diana)

"O Pibid é um trabalho, e muitas pessoas pensam porque é bolsa, é bolsa, mas é um trabalho e, a partir do momento que você leva essa responsabilidade, é o que você leva pra dentro da sala de aula como professor, e você tem que saber por que seus alunos não estão aprendendo." (Cibele)
\end{abstract}

Parece, portanto, que o Pibid propiciou uma relação com a turma e com os/as alunos/as mais intensa do que no estágio e mais próxima à de professora, com maior responsabilidade, inclusive a de se indagar por que os/ as estudantes não estavam aprendendo (uma função específica da professora). Apropriar-se das turmas é, assim, mais uma forma de a docência pibidiana se tornar mais parte destas e ganhar sentido.

Um aspecto apontado em diferentes momentos pelas entrevistadas é característico do Pibid: a ânsia por se colocar, por realizar, por experimentar. Cibele conta que foi advertida por uma das professoras para não falar tudo o que pensava: "Tem que se acostumar com o sistema, vocêfaz debaixo dos panos". Ao que retrucou que não era empregada do Estado, então poderia falar. Ao contrário do que se suporia, parece que por vezes a fragilidade é maior para uma professora, que não consegue se colocar nas reuniões com a equipe escolar, do que para uma pibidiana, que não tem emprego a perder. Embora a equipe do Pibid, assim como a professora, tenha de manter boas 
relações com a escola, para que possa continuar atuando e sobrevivendo nela, este trecho indica que há vias no Pibid que, por vezes, as professoras não conseguem acessar. Pode ser que haja também diferenças de posicionamentos entre a professora mencionada por Cibele e ela, talvez mais ousada e menos acuada pela necessidade de sobrevivência naquela equipe. Mas pode-se associar a vontade e ousadia de falar ao desejo de uma docência repleta de vontades, que muitas vezes já se esvaíram em professoras mais experientes, como bem colocou Diana: "A gente está cheia de ideias, a gente quer criar, quer fazer as coisas, vem com toda aquela vontade".

Ainda sobre as mediações propiciadas pelo Pibid, Diana e Ceres destacaram, para a condução das aulas, a importância do trabalho desenvolvido em duplas, que foi se estabelecendo ao longo dos três anos, no PPSC. O que ocorreu principalmente por solicitação das pibidianas, que se sentiam mais seguras, segundo seus relatos, ao darem suporte uma à outra. Ceres, mesmo provocada pela entrevistadora quanto à importância de conduzir uma turma sozinha, reafirma que o melhor é a atuação em dupla:

Ceres: "Em dupla, assim dá mais segurança, sabe?"

Pesquisadora: "Mas você parece que já está num momento que seria bom estar só, pra sentir um pouco."

Ceres: "Sozinha, né. Porque assim em dupla você tem mais segurança sabe? Se você se sente um pouco confusa, a pessoa vai lá e ajuda."

Os depoimentos das pibidianas indicam que a não solidão desse começo de docência no Pibid seria outra característica do terceiro espaço na formação docente. Além da atuação em dupla, já se indicou antes a valorização da interação com a supervisora, com a professora colaboradora e com as orientadoras da universidade.

Finalmente, à luz da análise dos excertos das entrevistas realizadas com as pibidianas, retorna-se à questão inicial: quais elementos do Pibid puderam proporcionar a expansão de sentidos para as pibidianas, tornando-se um terceiro espaço na formação docente?

\section{Algumas PONDERAÇões À GUISA DE CONSIDERAÇÕES FINAIS}

As relações entre o Pibid e a escola são alvo de muitas aprendizagens de certo tipo de docência que se concretiza no programa. As pibidianas parecem estar desenvolvendo algumas características que são consideradas fundamentais para uma profissionalidade reflexiva, intelectual, autônoma, ao se construírem como professoras autoras de suas práticas docentes, na medida em que buscam negociar com a escola os seus sonhos. Demonstraram, por meio de suas falas, o afã pela autoria, tanto nas regências do dia a dia quanto nos projetos e aulas propostos e planejados por elas. Essa autoria é voltada a uma escola que se quer, mas que faz suas opções no momento atual. Portanto, que não se adapta (SUCHODOLSKI, 1992, p. 129), consegue fazer críticas, algumas mais intuídas, outras mais elaboradas, à escola real.

Ainda sobre as relações entre o Pibid e a escola, os relatos indicam o trilhar de uma via diferente de muitas das propostas que chegam à escola pública, segundo Ceres afirmou. As negociações com a escola, o respeito e reconhecimento por parte do programa e de quem nele atua sobre os saberes das professoras e seu caráter permanente (é política implantada por decreto presidencial desde 2010) vêm viabilizando uma relação respeitosa e frutífera entre a escola e a universidade.

A autoria conquistada no Pibid constitui-se em diferentes aspectos, que as entrevistadas insistiram, acertadamente, em diferenciar dos estágios. Uma participação mais longa e intensa no contexto escolar propiciou a percepção mais ampliada, madura e compreensiva da docência e dos elementos da cultura escolar. Permitiu-lhes conhecer mais o projeto pedagógico da escola, planejar e conduzir uma aula, acompanhar turmas e estudantes com dificuldades ao longo de pelo menos um ano, respeitar e valorizar as professoras que as recebiam, registrar as reflexões sobre a própria prática e vivenciar um início de docência mais coletivo e menos solitário, representado pelas diferentes mediações com pares, professoras, diretora e orientadora da universidade.

Dessa forma, os significados aprendidos no curso de Pedagogia e na atuação no Pibid, que preocupam tanto no início da docência, tornaram-se fundamentais para a formação dessas professoras. Então, pode-se dizer que a expansão da atividade propiciada pelo Pibid foi mais ampla do que usualmente é possível nos estágios, constituindo-se, assim, no que Zeichner (2010) considerou um terceiro espaço de formação, que articula teoria e prática. Considera-se que essa expansão, esse novo espaço, é muito promissor, não só no que se refere à formação inicial, mas também no que diz respeito ao aprimoramento da educação básica.

\section{REFERÊNCIAS}

BOGDAN, R.; BIKLEN, S. Qualitative research for education. Boston: Allyn and Bacon, 1982.

DANIELS, H. Vygotsky e a pesquisa. São Paulo, Loyola, 2011. 
ENGESTRÖM, Y. The future of activity theory. In: DANIELS, $H$.; GUTIÉRREZ, $K$. Learning and Expanding with Activity Theory. New York: Cambridge, 2009.

NEVES, C. M. C. A Capes e a formação de professores para a educação básica. Revista Brasileira de Pós-Graduação, Brasília, supl. 2, v. 8, p. 353-373, mar. 2012.

SUCHODOLSKY, B. A Pedagogia e as grandes correntes filosóficas. Lisboa: Livros Horizonte, 1992.

VYGOTSKY, L. S. Teoria e método em Psicologia. 3. ed. São Paulo: Martins Fontes, 2004.
VYGOTSKY, L. S. A formação social da mente: o desenvolvimento dos processos psicológicos superiores. 7. ed. São Paulo: Martins Fontes, 2007.

ZEICHNER, K. Repensando as conexões entre a formação na universidade e as experiências de campo na formação de professores em faculdades e universidades. Educação. Santa Maria, v. 35, n. 3, p. 479-504, set./dez. 2010.

Submetido em 07/04/2015

Aprovado em 03/02/2016 